\title{
Reliability of HOME FAST BRAZIL-Self-Reported Version for Community-Dwelling Older Adults
}

\section{OPEN ACCESS}

Edited by:

Giuseppe Liotta,

University of Rome Tor Vergata, Italy

Reviewed by:

Susanna Gentili,

University of Rome Tor Vergata, Italy

Massimo Maurici,

University of Rome Tor Vergata, Italy

*Correspondence:

Karina Stella Aoki Ferreira kato.ufpr@hotmail.com

Specialty section:

This article was submitted to Aging and Public Health,

a section of the journal

Frontiers in Public Health

Received: 22 May 2021 Accepted: 17 November 2021 Published: 08 December 2021

Citation:

Ferreira KSA, Gallo da Silva TT, Melo

Filho J, Bazanella NV,

Vojciechowski AS, Mackenzie L and

Gomes ARS (2021) Reliability of HOME FAST BRAZIL-Self-Reported Version for Community-Dwelling Older Adults. Front. Public Health 9:713202.

doi: 10.3389/fpubh.2021.713202

\begin{abstract}
Karina Stella Aoki Ferreira ${ }^{1 *}$, Tamires Terezinha Gallo da Silva ${ }^{2}$, Jarbas Melo Filho ${ }^{2,3}$, Natacha Verônica Bazanella ${ }^{4}$, Audrin Said Vojciechowski ${ }^{2}$, Lynette Mackenzie ${ }^{5}$ and Anna Raquel Silveira Gomes ${ }^{6}$

${ }^{1}$ Occupational Therapy Department, Federal University of Parana, Curitiba, Brazil, ${ }^{2}$ Masters and PhD Program in Physical Education-PPGEDF, Federal University of Paraná, Curitiba, Brazil, ${ }^{3}$ Faculty Inspirar, Curitiba, Brazil, ${ }^{4}$ Maternity Hospital Marieta Konder Bornhausen, Itajai, Brazil, ${ }^{5}$ Faculty of Health Sciences, University of Sydney, Lidcombe, NSW, Australia, ${ }^{6}$ Prevention and Rehabilitation in Physiotherapy Department, Masters and PhD Programs in Physical Education-PPGEDF, Federal University of Parana, Curitiba, Brazil
\end{abstract}

Objective: Verify the intra- and inter-rater reliability of the HOME FAST BRAZIL-Self-reported version and correlate household environmental risks with the history of falls by community-dwelling older adults.

Method: Cross sectional study with 50 community-dwelling older adults who were screened by the cut-off point of the Mini Mental State Exam and replied to the HOME FAST BRAZIL - Self-reported version using two evaluators, on three occasions. The reliability analysis was determined by the Intra-class Correlation Coefficient (ICC), considering ICC $>0.70$ as adequate. To test the correlations, the Spearman test was used.

Results: The mean age of the participants was $73.2 \pm 5.8$ years. The inter- rater reliability of HOME FAST BRAZIL-Self-reported version was ICC 0.83 (IC95\%, 0.70-0.90) and the Intra- reliability ICC 0.85 (IC95\%, 0.74-0.91). A risk of falls was verified in $88 \%$ of the sample and four environmental risks presented significant correlations with the history of falls.

Conclusions: The HOME FAST BRAZIL-Self-reported version presented adequate reliability for the evaluation of household environmental risks for community-dwelling older adults. Risks such as inadequate armchairs/ sofas, the absence of anti-slip mats in the shower recess, the presence of pets and inadequate beds require attention in the evaluation of household risks, due to their correlation with the occurrence of falls.

Keywords: accidental falls, aged, reproducibility of results, risk assessment, environmental hazards, risk factors

\section{INTRODUCTION}

Falls are common events amongst the community-dwelling older adults, and can cause injuries and fractures leading to a decline in functional capacity, compromising independence and causing considerable health costs (1-4). The etiology of falls is multifactorial, resulting from the interaction between intrinsic and extrinsic factors, the risk increasing linearly with the number of factors which older adults are exposed to Moreira et al. (5) and Phelan et al. (6). Intrinsic factors are related to 
dysfunctions in systems that contribute to postural control (sensory, musculoskeletal, and central nervous system) (3).

The environmental risks present in the households of the older adults are linked to the occurrence of falls $(1,7)$. International guidelines recommend the evaluation of household risks as part of an efficient multifactorial approach for fall prevention $(8,9)$. Studies have confirmed the effectiveness of household environmental interventions in the reduction of falls by the community-dwelling older adults, and verified that the use of valid instruments that identify environmental risks and circumstances in a standardized way, is one of the fundamental aspects for the prevention of falls $(10,11)$.

A study found that among the standardized instruments developed to assess the residential risks of falls in the older adults, the Home Fall and Accidents Screening Tool (HOME FAST) (12) is one of the instruments with high potential for evaluating home hazards associated with falls (13). This instrument was translated and culturally adapted to Brazilian Portuguese (14), however, the need for home visits for its application is a limiting factor $(15,16)$.

To allow the evaluation of the risk of falls without visiting the homes of the community-dwelling older adults, researchers adapted the HOME FAST and developed the Home Falls and Accidents Screening Tool (HOME FAST) Self-Report Version, a tool in the English language which allows for the evaluation, in a self-reported way, of household environmental risk factors (17). This tool was translated and culturally adapted for Brazilian Portuguese with the title HOME FAST BRAZIL-Self-report Version (HOME FAST BRAZIL-SR) (18), but its measurement properties have not yet been verified.

One of the measurement properties required to guarantee the quality of an evaluation tool is reliability, which refers to the capacity to reproduce consistent results under different conditions, by the same evaluator or by different evaluators $(19,20)$.

Thus, the objective of this study was to verify the intra- and inter- rater reliability of HOME FAST BRAZIL-Self-reported version, in Brazilian community-dwelling older adults. Secondly, we aimed to correlate household environmental risks with the history of falls.

\section{METHODS}

\section{Sample Selection}

This is a research using a cross-sectional design, developed based on the Strengthening the Reporting of Observational studies in Epidemiology-STROBE. Older adults (over 60 years old) of both genders were included, all residents in the community, with adequate visual acuity and with availability to take part in the steps of the research. Individuals who missed one of the research steps and/or who did not reach the cut-off point of the Mini Mental State Exam (Brazilian version) (21) according to their scholastic level (a score of 13 for illiterate people, 18 for those with 1 to 7 years of schooling and 26 for individuals with 8 or more years of schooling), were excluded from the research.

The participants were recruited using convenience sampling, via projects operating within available by the community, and included at least 50 participants according to the sample number recommended for reliability studies $(19,22)$.

\section{Ethical Issue}

Data collection was carried out by interviews from April to July, 2018, in Curitiba-PR, Brazil, in locations such as the Outpatients Hospital of the Federal University of Parana (while the participants waited to be called in to the Physiotherapy Sector; in a church in the suburb of Capão Raso (while the participants waited for physical training made available for the community); and older adults invited for events at SESC in Água Verde and in Rua da Cidadania Pinheirinho. Preliminarily, the invitation to participate in the research was carried out and, in case of acceptance, the older people presented their consent by signing along with the Term of Free and Clarified Consent. The identification data of the participants were filled in, including the full name, gender, age, telephone and scholastic level.

This study was approved by the Ethics in Research Committee of the Faculdade Pequeno Principe, Curitiba (PR), Brazil, according to protocol 1.960.06, and by the Ethics in Research Committee of the Municipal Health Secretariat of Curitiba, Curitiba (PR), Brazil, according to protocol 2.083.84.

\section{Measurements}

Information concerning visual acuity adequacy (self-reported) was also obtained and a cognitive selection process applied by way of the Mini Mental State Test. And body mass; height and body mass index (BMI). In addition, an evaluation of the selfreported history of falls was carried out to investigate correlations with environmental risks. The participants were questioned about the occurrence of falls in the last 12 months prior to the evaluation day as well as the number of falls, the place where they occurred and the cause (9).

The risk of falls was evaluated using Home Falls and Accidents Screening Tool Self-report version (HOME FAST-SR) (17), in its Brazilian Portuguese version, HOME FAST BRAZIL-SR (18). The tool has 20 questions subdivided into 97 items, for which the older people participants have to reply "yes" or "no." The questions evaluate the presence of household environmental dangers, considering mats, floors, steps, objects on the floor, inadequate furniture, lighting, bathroom safety, cupboards, stairs and pets, as well as risky behavior, corresponding to 25 domains derived from Home Falls and Accidents Screening Tool for Health Professionals (HOME FAST-HP) (17). A method has been developed to transform scores from the HOME FASTSR. i.e., to convert the 97 items to the 25 domains of HOME FAST-HP score. Both the HOME FAST-SR instrument and the transformation method are available at: http://hdl.handle.net/ $2123 / 17635$. A final score equal or above to 9 indicates a risk of falls in the household (18).

To test the reliability of HOME FAST BRAZIL-SR, the tool was applied to all participants on three different occasions. The tool was applied by two raters (evaluator 1 and evaluator 2) to analyze inter-rater reliability on the same day, independently, with an interval of $40 \mathrm{~min}$. The intra-rater reliability was determined by applying the tool by the same evaluator (evaluator 


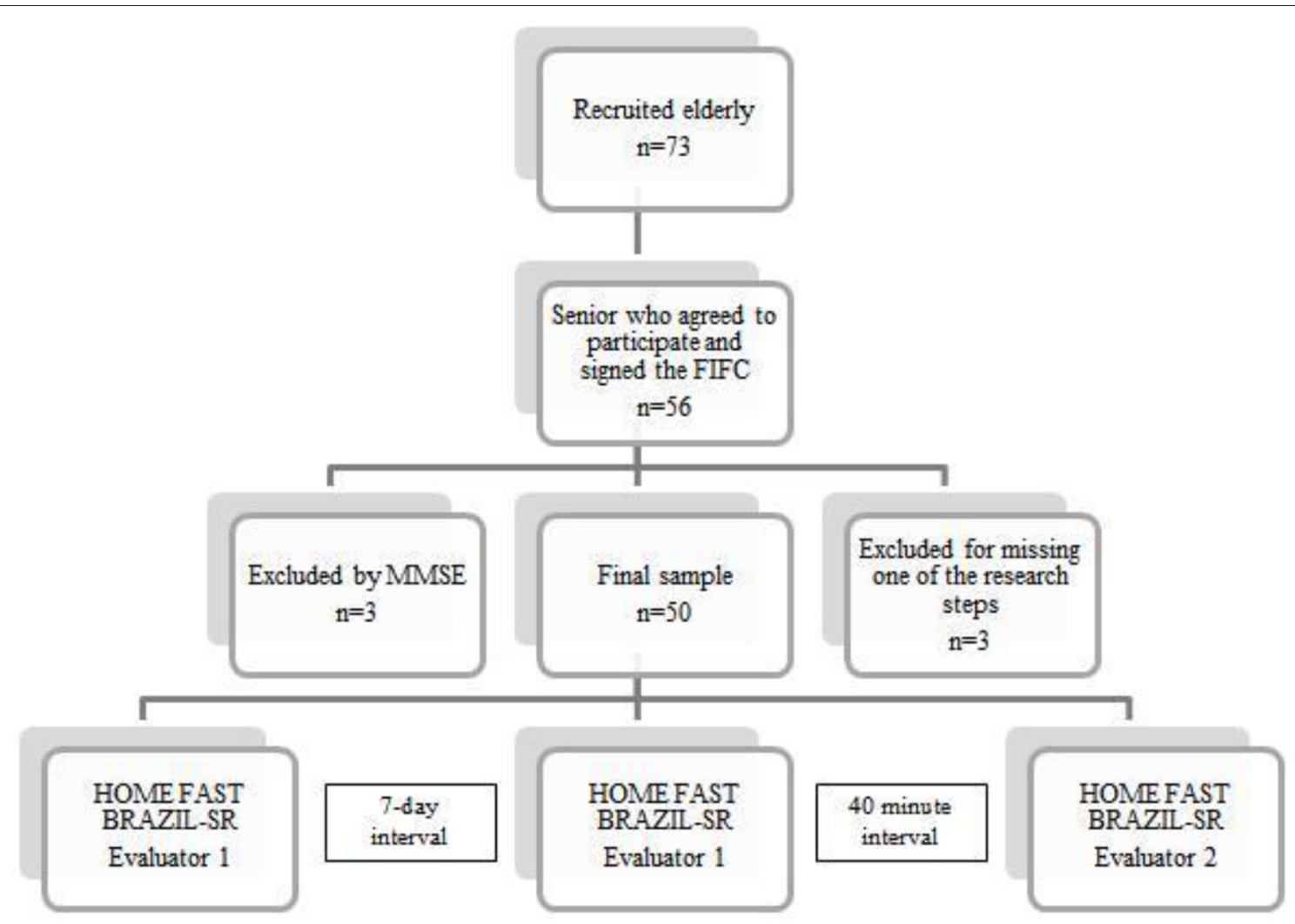

FIGURE 1 | Study flow sheet. $n$, number of people; FICF, Free and Informed Consent Form; MMSE, Mini Mental State Exam.

1) on two different occasions, with an interval of 7 days between applications (23).

\section{Statistical Analysis}

The data were analyzed by descriptive statistics using the Statistical Package for the Social Sciences (SPSS) software, version 20.0, providing the mean, standard deviation and the absolute and relative frequencies. The normality of the data distribution was analyzed by the Shapiro Wilk Test, considering the data normal if $p>0.05$.

The statistical analysis was run based on the total number of falls, considering both at home and out of home. The $T$ test for Independent Samples was used to compare the variables presenting a normal distribution and for the categorical data was used the Chi-square or Fisher's exact test, considering $p \leq 0.05$. For the parametric variables, the correlations were tested by the Pearson's Test, and for non-parametric, the Spearman's Test was used, considering $p \leq 0.05$.

The reliability analysis was determined by the Intraclass Correlation Coefficient (ICC), considering ICC $>0.70$ as adequate $(23,24)$. The Bland-Altman Dispersion Diagram was used to evaluate the magnitude of the differences between the scores obtained in the intra- and inter-rater reliability applications, with the expectation that the values were parallel around the zero horizontal axis and within the confidence limits (23).

\section{RESULTS}

Figure 1 shows the flow sheet of the study. Seventy-three community-dwelling older adults were invited to participate in the research, of which 17 refused due to a lack of availability. A further 3 were excluded for not reaching the minimum score in the Mini Mental State Exam and a further 3 were excluded because they missed one of the steps of the research. Thus, 50 older adults took part in the study with a mean age of $73.2 \pm 5.8$ years, of which $84 \%(n=42)$ were female and $16 \%(n=8)$ male. The sociodemographic characteristics of the participants, divided by gender, can be seen in Table 1 .

The scores obtained for the HOME FAST BRAZIL-SR at the three evaluation occasions were: evaluator 1 (9.9 \pm 2.4 ); evaluator 2 (10.6 \pm 2.5$)$; evaluator 1 after 7 days (10.2 \pm 2.3). The Inter-reliability was ICC $0.83(0.70-0.90)$ and the Intra-evaluator reliability was ICC $0.85(0.74-0.91)$. Figure 2 presents the Bland Altman Dispersion Diagrams, which show the magnitude of the variability between the intra- and inter-rater reliability measurements using the HOME FAST BRAZIL-SR.

Regarding the history of falls, 18 participants (36\%) reported at least one fall in the last year. Of the total number (18; being 17 women fallers and 1 men faller; with average age of 74.61 \pm 5.67 years old; stature $1.56 \pm 0.06$ meters; body mass 70.21 $\pm 15.68 \mathrm{~kg}$; BMI $28.86 \pm 4.96 \mathrm{~kg} / \mathrm{m}^{2}$; and $66.7 \%(n=12)$ with incomplete elementary school) of falls reported, $54.8 \%$ occurred 
TABLE 1 | Characteristics of the sample.

\begin{tabular}{|c|c|c|c|c|}
\hline & Female $(n=42)$ & Male $(n=8)$ & Total $(n=50)$ & $p$ \\
\hline Stature $(m)^{\dagger}$ & $1.57 \pm 0.06$ & $1.68 \pm 0.03$ & $1.59 \pm 0.07$ & $0.00^{*}$ \\
\hline $\mathrm{BMI}\left(\mathrm{Kg} / \mathrm{m}^{2}\right)^{\dagger}$ & $29.12 \pm 7.34$ & $30.23 \pm 5.98$ & $29.30 \pm 7.09$ & 0.68 \\
\hline \multicolumn{5}{|l|}{ Education ${ }^{\ddagger}$} \\
\hline Incomplete high school & $2.4 \%(n=1)$ & - & $2 \%(n=1)$ & \\
\hline Complete high school & $23.8 \%(n=10)$ & $12.5 \%(n=1)$ & $22 \%(n=11)$ & \\
\hline Complete high school & $9.5 \%(n=4)$ & $12.5 \%(n=1)$ & $10 \%(n=5)$ & \\
\hline
\end{tabular}

BMI, Body Mass Index; ${ }^{\dagger}$ mean values \pm standard deviation compared by T-test for Independent Samples; ${ }^{\ddagger}$ Relative (\%) and absolute (number) frequency values by chi-square or Fisher's exact test. * Significant difference.
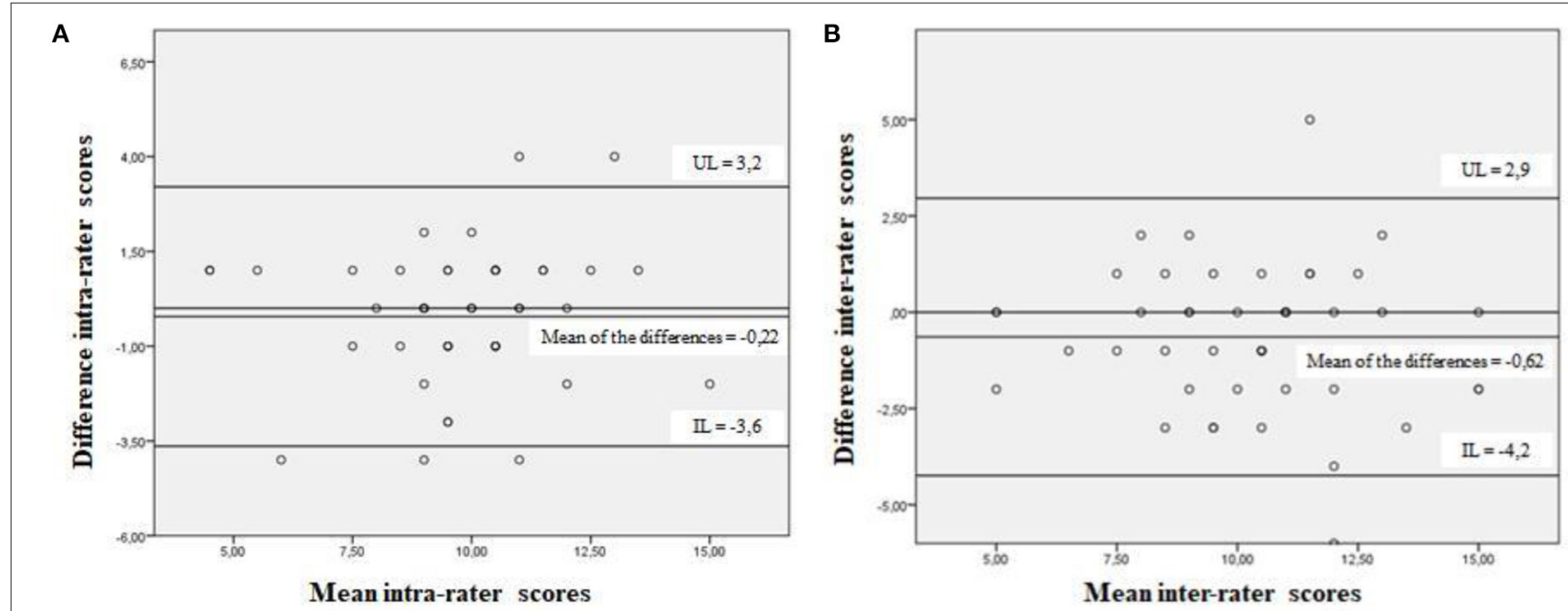

FIGURE 2 | Bland-Altman dispersion diagram with the magnitude of variability between the intra-rater (A) and inter-rater (B) measurements of the HOME FAST BRAZIL-SR. Curitiba, Paraná, 2018. UL, upper limit; IL, inferior limit.

on roads and $45.1 \%$ in the participant's own home. Self-reported factors responsible for these falls were, $67.7 \%$ occurred due to environmental risks (stumbling or slipping); $25.8 \%$ due to intrinsic factors (loss of balance or dizziness); and $6.4 \%$ due to behavioral factors (climbing up onto a stool or steps to carry out domestic chores).

The mean score for the evaluation of the risk of falls according to the HOME FAST BRAZIL-SR was $9.98 \pm 2.41$, being $9.7 \pm 2.4$ for females and $11 \pm 2.3$ for males, with no significant difference between genders ( $\mathrm{t}: 11.34 ; p=0.208$, t-test for independent samples). A total of 44 of the participants (88\%) presented a score equal or $>9$ indicating a high risk of falls. The frequency of hazards related to falls reported by the participants, through the application of HOME FAST BRAZIL-SR, are shown in Figure 3.

The following environmental risks showed significant correlations with the number of falls that occurred in households: presence of inadequate armchairs/sofas $(r=0.76 ; p=0.01$,
Spearman), absence of an anti-slip mat in the shower recess ( $r$ $=-1.00 ; p<0.001$, Spearman) and needing various attempts to manage to get up from the armchair/sofa $(r=0.66 ; p=0.03$, Spearman). The following risk showed significant correlation with the general number of falls (in the household and on the street): needing more than one attempt to get up from bed ( $r=$ $0.47 ; p=0.04$, Spearman). The history of falls (in the last year) also showed a significant correlation with the presence of pets in the household ( $r=0.40 ; p=0.003$, Spearman).

\section{DISCUSSION}

The reliability of HOME FAST BRAZIL-Self-reported version was tested in Brazilian community-dwelling older adults and the results indicated that the tool had adequate intra and inter rater reliability to evaluate household environmental risks. Studies that evaluate the measurement properties of evaluation tools 


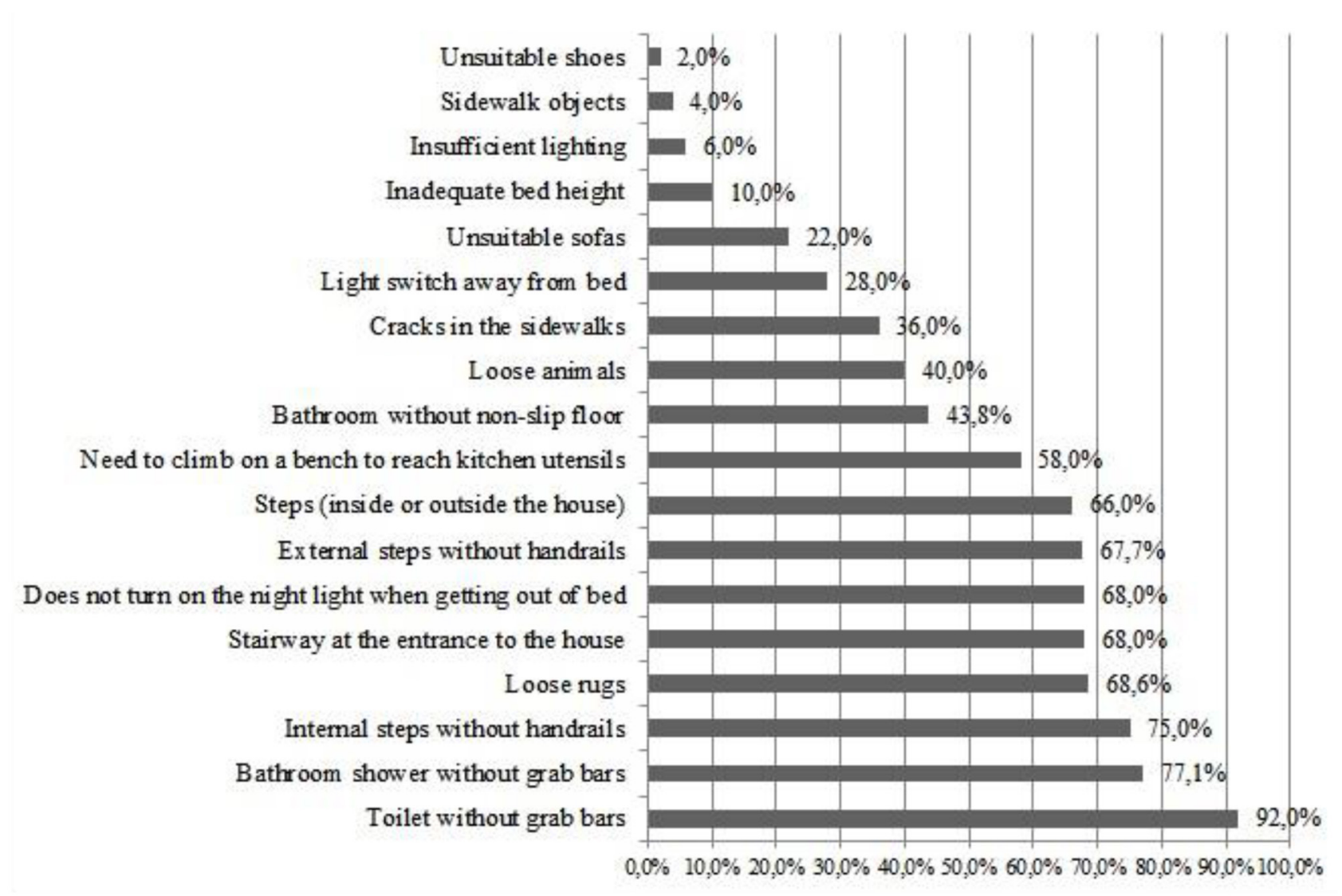

FIGURE 3 | Percentage (\%) of risks identified using HOME FAST BRAZIL-SR. Curitiba, Paraná, 2018.

with respect to health, such as reliability, provide important information concerning the quality of the tool and determine the choice for application by health researchers and professionals (20, 23). For a test to be considered reliable, it should provide precise and reproducible information by both the same examiner-intrarater reliability and different examiners-inter-rater reliability (21). In the present study, the results obtained in the verification of the intra-rater and inter-rater reliability confirmed the capacity of HOME FAST BRAZIL-SR to be reproducible both by the same evaluator on distinct occasions and by different evaluators. Good to excellent test-retest reliability was demonstrated for HOME FAST BRAZIL-SR, filling an important gap of the literature, considering that it is the only published self-assessment of the home environment's factors for falls in Brazilian Portuguese. Identifying home hazards by self-report has the potential for older people to increase their awareness of the safety of their home environment, which may lead to more immediate negative effects, such as an older person feeling more vulnerable in their home to plan the changes (17).

Considering the recommendations based on evidence for the multidimensional evaluation of the health of older adults (25), the HOME FAST BRAZIL-SR stood out as an important tool to optimize the screening process for the risk of falls and identify Brazilian community-dwelling older adults at risk, making it possible to prevent future health problems. Falls are amongst the main threats to the health of the older people, being responsible for $95 \%$ of hip fractures (3), a fact which made the need for early risk screening urgent.

The present study found a high prevalence of risk, since $88 \%$ of the older adults evaluated scored 8 or above in the HOME FAST BRAZIL-SR, the mean score found being 9.9. Similar risk levels were found earlier, where a mean score of 9.4 was found using the same tool in a sample of 568 community-dwelling older adults in Australia (17).

The household fall risks found in the present research are aligned with other research findings $(7,17,18,26)$, the majority being difficult to modify. Earlier studies $(6,27)$ emphasized the need for intervention in modifiable risk factors for falls, showing that the installation of handrails on stairs, grab bars in bathrooms and non-slip ground coverings in external areas reduced the injury and fracture rates caused by falls.

In the present study, risks such as inadequate armchairs/sofas, the absence of anti-slip mats in shower recesses, the presence of pets and inadequate beds stood out for their association with the occurrence of falls. The number of dangers in a household indicates the degree of exposure of a person to the possibility of falling and the risks associated with falls deserve attention, since they could be contributing to the occurrence of falls (18). 
An earlier study showed that the presence of pets in the main entrance to a home was significantly associated with the occurrence of falls in the older adults and increased the chance of falling by a factor of two (28). Risks involving pets were reported by $85.6 \%$ of the sample of 567 community-dwelling older adults (18). In the present study, $40 \%$ of the older adults presented risks related to the presence of pets, a fact correlating with the history of falls (having fallen during the previous year). These data are a sign of the need to pay more attention to this aspect in the evaluation of community-dwelling older adults so that preventative strategies can be developed.

According to the present study, the older adults who reported difficulty in getting up from bed or from armchairs/ sofas, requiring more than one attempt in order to stand up, suffered more falls in their own homes. Not managing to get up from the bed or from armchairs/ sofas on the first attempt is as much related to a possible inadequacy of the furniture as to mobility alterations in the older person (12). Aging is associated with a reduction in skeletal muscle mass and in muscle strength and power, especially that of the knee extensor muscles, in which a 20 to $40 \%$ reduction in strength and power up to the seventh decade of life has been found. This interferes in mobility, functional capacity, and the satisfactory carrying out of sitting down and getting up activities $(29,30)$. Older people who show the worst results in the sit down and get up from a chair in $30 \mathrm{~s}$ test, present inferior functional performance in the carrying out of their daily life activities and their instrumental daily life activities (31). Therefore, we suggest that future studies should carry out physical-functional performance evaluations together with the HOME FAST BRAZIL-SR in order to clinically verify if the strength and power of the lower limbs require physical training to increase the capacity to sit down and get up from bed or from armchairs/ sofas.

In the present study, the older adults who did not use an anti-slip mat in the bathroom referred to a larger number of falls inside their homes. Earlier studies reported the absence of anti-slip mats in the households of community-dwelling older adults as being prevalent $(18,28)$. The existence of slippery floors in the homes of the older adults is a factor of risk that should be identified and eliminated, since it is implicated in falls and fractures (32).

The epidemiological aspects of falls were described in a study with 324,060 community-dwelling older adults in the State of Victoria, Australia, showing that $80.7 \%$ of falls were caused by environmental risks and the home was the most common location for this to occur (33). In the present study, environmental risks were involved in the majority $(67.7 \%)$ of the falls reported by the community-dwelling older adults, and were responsible for half (50\%) of the falls occurring in the person's own home and for the great majority $(82.3 \%)$ of the falls occurring in the road. Similar results were found in an earlier study (34) which showed that the majority of falls in external environments were caused by environmental risks due to tripping and slipping on sidewalks, curbs and irregular surfaces. Generally, falls occurring in the road or in external environments are related to environmental aspects, whereas falls occurring in the home are more related to the individual's state of health
(34-36). The older people who fall in their own homes present worse physical performance and functional mobility as compared to those who fall in the road when tests such as the Timed Up and Go test (TUG), Berg's Equilibrium Scale, Short Physical Performance Battery (SPPB) and Gait velocity are used $(36,37)$. Thus, the need for measures that improve accessibility in the community are apparent, since the majority of falls that occur in the road are caused by modifiable factors, the implementation of actions that eliminate risks involving sidewalks, curbs and roads being fundamental, with the restoration of irregular surfaces, removal of obstacles and installation of ramps $(34,37)$.

Therefore, indoor and outdoor falls are a complex event and occur when environmental hazards, tasks or demands exceed the individual's ability to maintain postural control. Due to this complexity, any falls prevention interventions need to take a multi-factorial, individually tailored approach to address a range of risk factors (18).

In addition to the environmental and intrinsic factors of risk, the present study found a high frequency of behavioral risks, such as not switching on a light when getting up at night (68\%), and getting up onto a stool or other object to reach utensils for use in the kitchen (58\%). Apart from these, 14.2\% of the falls occurring in the person's own home were caused by attitudes such as getting up onto a stool or portable steps when carrying out domestic chores. Risky behavior includes attitudes adopted by the community-dwelling older adults which expose them to a greater chance of falling $(12,38)$. The items in the HOME FAST BRAZIL-SR cover risk categories such as environmental factors, functional factors and behavioral factors (17). Evaluations of household falls should include the investigation of behavioral factors, since domestic safety involves both the nature of the physical characteristics of the environment and the way in which a person interacts with it (12).

The present study has strengths that should be emphasized: HOME FAST BRAZIL-SR is the only self-reported instrument for assessing domiciliary risk of falls in the older people translated and adapted transculturally into Brazilian Portuguese that that presents adequate reliability, assuring its ability to reproduce consistent results by the same evaluator or by different evaluators. Moreover, the data showed that environmental hazards such as inadequate armchairs/sofas, the absence of anti-slip mats in the shower recess, the presence of pets and inadequate beds correlated with the occurrence of falls, contributing to health professionals to guide older people to determine changes, prevent, and diminish falls risk inside home, even without a previous visit at the residence.

The limitations of this study refer to the nature of HOME FAST BRAZIL-SR, by which the identification of household risks is carried out by self-reporting, which can suffer the influence of memory. The sample of the present study was mainly female, there were more women than men at the places where the sample was recruited. Thus, it can be suggested for future studies to balance the genders in the sample, and/or consider a proportionality according to recent demographic statistics. The little number of participants that experienced at least a fall in their home might be considered a limitation. Other measurement properties of the tool still need to be established in Brazil, such as 
the criterion validity and internal consistency (20). In addition, since this study was of a cross-sectional nature, a cause and effect relationship could not be established, and hence it could not be affirmed that the household environmental risks were modified after the occurrence of falls. Hence the authors suggest the carrying out of a longitudinal study using HOME FAST BRAZIL$\mathrm{SR}$, to produce evidence concerning the relationship between household environmental risks and the incidence of falls.

\section{CONCLUSION}

The HOME FAST BRAZIL-Self-reported Version presents adequate intra and inter-rater reliability, and can be used in clinical evaluations and in Brazilian research to identify older adults at risk for household falls. A risk of falls was found in $88 \%$ of the sample studied due to the presence of hazards in their households. Amongst the risks identified, the high frequency of the absence of support bars at the side of toilets, the absence of support bars in shower recesses, the absence of handrails on internal steps and loose mats stood out. Risks such as inadequate armchairs/ sofas, the absence of anti-slip mats in shower recesses, the presence of pets and inadequate beds also deserve attention in the evaluation of household risks, since they have shown correlation with the occurrence of falls.

\section{DATA AVAILABILITY STATEMENT}

The raw data supporting the conclusions of this article will be made available by the authors, without undue reservation.

\section{ETHICS STATEMENT}

The studies involving human participants were reviewed and approved by Research Ethics Committee of the Pequeno Príncipe College, Curitiba, Paraná, Brazil (number 1.960.069/2017), and

\section{REFERENCES}

1. Cockayne S, Pighills A, Adamson J, Fairhurst C, Drummond A, Hewitt C, et al. Can occupational therapist-led home environmental assessment prevent falls in older people? A modified cohort randomised controlled trial protocol. BMJ Open. (2018) 8:1-11. doi: 10.1136/bmjopen-2018-022488

2. Cuevas-Trisan R. Balance problems and fall risks in the elderly. Physical medicine and rehabilitation clinics of North America. Phys Med Rehabil Clin N Am. (2017) 28:727-37. doi: 10.1016/j.pmr.2017.06.006

3. World Health Organization (WHO). World Report on Ageing and Health. Geneva: WHO (2015). Available online at: http://www.who.int/ageing/events/ world-report-2015-launch/en/ (accessed October 03, 2018).

4. Hoff M, Meyer HE, Skurtveit S, Langhammer A, Sogaard AJ. Validation of FRAX and the impact of self-reported falls among elderly in a general population: the HUNT study, Norway. Osteoporos Int. (2017) 28:293544. doi: 10.1007/s00198-017-4134-9

5. Moreira MN, Bilton TL, Dias RC, Ferriolli E, Perracini MR. What are the main physical functioning factors associated with falls among older people with different perceived fall risk? Physiother Res Int. (2017) 22:111. doi: $10.1002 /$ pri. 1664 by the Research Ethics Committee of the Health Department of the City of Curitiba, Curitiba, Paraná, Brazil (number 2.083.841/2017). The patients/participants provided their written informed consent to participate in this study.

\section{AUTHOR CONTRIBUTIONS}

$\mathrm{KF}, \mathrm{NB}, \mathrm{JM}, \mathrm{AV}, \mathrm{LM}$, and AG participated in the conception, design, analysis, and interpretation of data. KF and TG collected the data. AG participated in the conception and study design, drafting the article, and revising it critically. The authors read and approved the final manuscript.

\section{FUNDING}

This study was financed in part by the Coordenacão de Aperfeicoamento de Pessoal de Nível Superior - Brasil (CAPES) - Finance Code 001; Residence fellowship from the Brazilian Ministry of Health; Productivity Research fellowship from the National Council for Scientific and Technological Development $(\mathrm{CNPq})$ and Pró-Reitoria de Pesquisa e Pósgraduação (PRPPG) at the Federal University of Paraná (UFPR) for the payment of the publication fee.

\section{ACKNOWLEDGMENTS}

The authors are grateful for older people that took part of this study. The Professor Silvia R. Valderramas from the Department of Prevention and Rehabilitation in Physiotherapy at the Federal University of Paraná and Professor Adriano Eduardo Lima da Silva from the Department of Physical Education at the Federal Technological University of Paraná for the methodological support. The Professor Mônica M. de Macedo Ignácio, chief of the Occupational Therapy Department at the Federal University of Paraná, for the authorization for the training license.
6. Phelan EA, Mahoney JE, Voit JC, Stevens JA. Assessment and management of fall risk in primary care settings. Med Clin North Am. (2015) 99:28193. doi: 10.1016/j.mcna.2014.11.004

7. Rossetin LL, Rodrigues EV, Gallo LH, Macedo DS, Schieferdecker MEM, Pintarelli VL, et al. Indicators of sarcopenia and their relation to intrinsic and extrinsic factors relating to falls among active elderly women. Rev Bras Geriatr Gerontol. (2016) 19:399-414. doi: 10.1590/1809-98232016019.150028

8. American Geriatrics Society and British Geriatrics Society. Panel of falls in older persons American Geriatrics Society and British Geriatrics Society. Summary of the Updated American Geriatrics Society/British Geriatrics Society clinical practice guideline for prevention of falls in older persons. $J$ Am Geriatr Soc. (2011) 59:148-57. doi: 10.1111/j.1532-5415.2010.03234.x

9. Stevens JA, Burns ER. A CDC Compendium of Effective Fall Interventions: What Works for Community-Dwelling Older Adults. 3rd ed. Atlanta, GA: Centers for Disease Control and Prevention, National Center for Injury Prevention and Control (2015).

10. Cumming RG, Thomas M, Szonyi G, Salkeld G, O’Neill E, Westbury C, et al. Home visits by an occupational therapist for assessment and modification of environmental hazards: a randomized trial of falls prevention. J Am Geriatr Soc. (1999) 47:1397-402. doi: 10.1111/j.1532-5415.1999.tb01556.x 
11. Clemson L, Mackenzie L, Ballinger C, Close JC, Cumming RG. Environmental interventions to prevent falls in community-dwelling older people. J Aging Health. (2008) 20:954-71. doi: 10.1177/0898264308324672

12. Mackenzie L, Byles J, Higginbotham N. Designing the Home Falls and Accidents Screening Tool (HOME FAST): selecting the items. Br J Occup Ther. (2000) 63:1-10. doi: 10.1177/030802260006300604

13. Romli MH, Mackenzie L, Lovarini M, Tan MP, Clemson L. The Clinimetric Properties of instruments measuring home hazards for older people at risk of falling: a systematic review. Eval Health Prof. (2018) 41:82128. doi: $10.1177 / 0163278716684166$

14. Melo Filho J, Valderramas S, Vojciechowski AS, Mackenzie L, Gomes ARS. The Brazilian version of the Home Falls and Accidents Screening Tool (HOME FAST): translation, cross-cultural adaptation, validation and reliability. Rev Bras Geriatr Gerontol. (2020) 23:1-14. doi: 10.1590/1981-22562020023.190180

15. Stevens M, Holman J, Bennett N. Preventing falls in older people: impact of an intervention to reduce environmental hazards in the home. J Am Geriatr Soc. (2001) 49:1442-7. doi: 10.1046/j.1532-5415.2001.4911235.x

16. Moylan KC, Binder EF. Falls in older adults: risk assessment, management and prevention. Am J Med. (2007) 6:493-7. doi: 10.1016/j.amjmed.2006.07.022

17. Mehraban AH, Mackenzie LA, Byles JE. A self-report home environment screening tool identified older women at risk of falls. J Clin Epidemiol. (2011) 64:191-9. doi: 10.1016/j.jclinepi.2010.02.013

18. Mackenzie L, Byles J. Scoring the home falls and accidents screening tool for health professionals (HOME FAST-HP): evidence from one epidemiological study. Aust Occup Ther J. (2018) 65:346-53. doi: 10.1111/1440-1630.12467

19. Melo Filho J, Bazanella NV, Vojciechowski AS, Costa ERR, Mackenzie L. Gomes ARS. The HOME FAST BRAZIL self-report version: translation and transcultural adaptation into Brazilian Portuguese. Adv Rheumatol. (2020) 60:1-7. doi: 10.1186/s42358-020-00130-y

20. Mokkink LB, Terwee CB, Patrick DL, Alonso J, Stratford PW, Knol DL, et al. The COSMIN checklist for assessing the methodological quality of studies on measurement properties of health status measurement instruments: an international Delphi study. Quality Life Res. (2010) 19:53949. doi: 10.1007/s11136-010-9606-8

21. Scholtes VA, Terwee CB, Poolman RW. What makes a measurement instrument valid and reliable? Injury. (2010) 42:236-40. doi: 10.1016/j.injury.2010.11.042

22. Bertolucci PHF, Brucki SMD, Campacci SR, Juliano Y. The Mini-Mental State Examination in an outpatient population: influence of literacy. Arq Neuro Psiquiatr. (1994) 52:1-7. doi: 10.1590/S0004-282X1994000100001

23. Terwee $\mathrm{CB}$, Bot SD, de Boer MR, van der Windt DA, Knol DL, Dekker J, et al. Quality criteria were proposed for measurement properties of health status questionnaires. J Clin Epidemiol. (2007) 60:34-42. doi: 10.1016/j.jclinepi.2006.03.012

24. Landis JR, Koch GG. The measurement of observer agreement for categorical data. Biometrics. (1977) 33:159-74. doi: 10.2307/2529310

25. World Health Organization (WHO). Integrated Care for Older People: Guidelines on Community-Level Interventions to Manage Declines in Intrinsic Capacity. Geneva: World Health Organization (2017). Available online at: http://www.who.int/ageing/publications/guidelines-icope/en/ (accessed October 03, 2018).

26. Carter SE, Campbell EM, Sanson-Fisher RW, Redman S, Gillespie WJ. Environmental hazards in the homes of older people. Age Ageing. (1997) 26:195-202. doi: 10.1093/ageing/26.3.195

27. Keall MD, Pierse N, Howden-Chapman P, Cunningham C, Cunningham M, Guria J, et al. Home modifications to reduce injuries from falls in the Home
Injury Prevention Intervention (HIPI) study: a cluster-randomised controlled trial. Lancet. (2015) 385:231-38. doi: 10.1016/S0140-6736(14)61006-0

28. Pereira SG, Santos CB, Doring M, Portella MR. Prevalence of household falls in long-lived adults and association with extrinsic factors. Rev Lat Am Enfermagem. (2017) 25:1-7. doi: 10.1590/1518-8345.1646.2900

29. Doherty TJ. Invited review: aging and sarcopenia. J Appl Physiol. (2003) 95:1717-27. doi: 10.1152/japplphysiol.00347.2003

30. Pimentel I, Scheicher ME. Comparison of mobility, muscle strength and fear of fall in falling and non-falling elderly. Rev Brasil Geriat Gerontol. (2013) 16:251-7. doi: 10.1590/S1809-98232013000200005

31. Santos RG, Tribess S, Meneguci J, Bastos LAG, Damião R, Virtuoso Júnior JS. Lower limb strength as an indicator of functional disability in older individuals. Motriz Rev Educ Fis. (2013) 19:35-42. doi: 10.1590/S1980-65742013000700006

32. Fares A. Pharmacological and non-pharmacological means for prevention of fractures among elderly. Int J Prev Med. (2018) 9:1-8. doi: 10.4103/ijpvm.IJPVM_114_18

33. Cox S, Roggenkamp R, Bernard S, Smith K. The epidemiology of elderly falls attended by emergency medical services in Victoria, Australia. Injury. (2018) 49:1712-9. doi: 10.1016/j.injury.2018.06.038

34. Li W, Keegan TH, Sternfeld B, Sidney S, Quesenberry Jr CP, Kelsey JL. Outdoor falls among middle-aged and older adults: a neglected public health problem. Am J Public Health. (2006) 96:1192-200. doi: 10.2105/AJPH.2005.083055

35. Kim SH. Risk factors for severe injury following indoor and outdoor falls in geriatric patients. Arch Gerontol Geriatr. (2016) 62:75-82. doi: 10.1016/j.archger.2015.10.003

36. Nascimento CF, Duarte YAO, Lebrão ML, Chiavegatto Filho ADP. Individual and contextual characteristics of indoor and outdoor falls in older residents of São Paulo, Brazil. Arch Gerontol Geriatr. (2017) 68:11925. doi: 10.1016/j.archger.2016.10.004

37. Kelsey JL, Berry SD, Procter-Gray E, Quach L, Nguyen USD Li W. Indoor and outdoor falls in older adults are different: the maintenance of balance, independent living, intellect, and Zest in the Elderly of Boston study. J Am Geriatr Soc. (2010) 58:2135-41. doi: 10.1111/j.1532-5415.2010.03062.x

38. Messias MG, Neves RF. The influence of behavior and domestic enviromental factors in elderly falls. Rev Bras Geriatr Gerontol. (2009) 12:27582. doi: 10.1590/1809-9823.2009.120210

Conflict of Interest: The authors declare that the research was conducted in the absence of any commercial or financial relationships that could be construed as a potential conflict of interest.

Publisher's Note: All claims expressed in this article are solely those of the authors and do not necessarily represent those of their affiliated organizations, or those of the publisher, the editors and the reviewers. Any product that may be evaluated in this article, or claim that may be made by its manufacturer, is not guaranteed or endorsed by the publisher.

Copyright (C) 2021 Ferreira, Gallo da Silva, Melo Filho, Bazanella, Vojciechowski, Mackenzie and Gomes. This is an open-access article distributed under the terms of the Creative Commons Attribution License (CC BY). The use, distribution or reproduction in other forums is permitted, provided the original author(s) and the copyright owner(s) are credited and that the original publication in this journal is cited, in accordance with accepted academic practice. No use, distribution or reproduction is permitted which does not comply with these terms. 